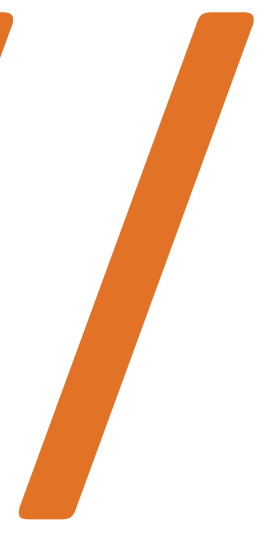

\title{
0 cinema
}

latino-americano de Chris Marker The Latin American cinema by Chris Marker

Tainah Negreiros Oliveira de Souza ${ }^{1}$ 
Resumo: Este texto aponta os principais aspectos trabalhados no recém lançado livro O cinema latinoamericano de Chris Marker, de Carolina Amaral de Aguiar, buscando explicitar a relevância de sua pesquisa e os caminhos percorridos pela autora para tratar da relação do cineasta francês Chris Marker com os movimentos sociais na América Latina nos anos 1960 e 1970; relação essa que contribuiu para a concepção de uma parte significativa da filmografia do cineasta e também para a concepção de filmes na América Latina.

Palavras-chave: Chris Marker; América Latina; ICAIC.

Abstract: This paper highlights the main aspects of Carolina Amaral de Aguiar's book The Latin American cinema by Chris Marker, seeking to make explicit the relevance of her research and the proposed ways by the author to analyze the relationship of French filmmaker Chris Marker with social movements in Latin America in the 1960s and 1970s. This relationship contributed to the conception of a significant part of the filmmaker's filmography and also to the conception of films here.

Keywords: Chris Marker; Latin America; ICAIC. 
Podemos demarcar a Mostra Chris Marker: bricoleur multimídia, ocorrida no Brasil em 2009, como um marco para uma crescente nos estudos sobre a obra do cineasta no Brasil. Nomes como Costa Júnior (2013), Koide (2011) e Leonel (2011; 2015) são exemplos de pesquisadores com trabalhos dedicados ao artista. Anterior a esse boom, Márcio Seligmann-Silva já havia dedicado um capítulo do livro História, memória, literatura: o testemunho na era das catástrofes (2003) para sublinhar a relação entre o filme La Jetée (1962), de Marker, e Walter Benjamin.

A historiadora Carolina Amaral de Aguiar (2016) compõe esse cenário ao investigar a relação de Chris Marker com a América Latina. O resultado de sua incursão sobre o tema pode ser conferido em $O$ cinema latino-americano de Chris Marker, lançado em 2016 como resultado de sua pesquisa de doutorado. No decorrer de seis capítulos, ela se dedicou àquilo que Olivier Compagnon chamou, na orelha desse livro, de "momento latino-americano na história europeia dos anos 1960 e 1970". Trata-se, acima de tudo, da investigação de uma relação, ou de relações, que, em medidas variadas, vão contribuir para produção de uma série de filmes de teor militante tanto na Europa quanto nos países latino-americanos com que Chris Marker se relacionou.

A conexão Chris Marker-Cuba é o enfoque do primeiro capítulo. Esse contato é elucidado, primeiramente, por meio da investigação do posicionamento do cineasta no contexto da esquerda francesa na virada para a segunda metade do século XX. A autora mapeia os contatos, influências e inspirações que compõem um cenário ao qual Chris Marker faz parte, associado a nomes como Jean-Paul Sartre, Agnès Varda, Gerárd Philipe, entre outros.

Um dos principais méritos do seu trabalho reside justamente nessa capacidade de mapear e nos oferecer um desenho em que convivem as ideias, os movimentos sociais organizados e a produção artística no cenário em que os vários trabalhos de Chris Marker foram concebidos.

Esse percurso introdutório guia a uma reflexão sobre o filme ¡Cuba Sí! (1961), por meio de uma abordagem que coloca em paralelo a relação entre linguagem fílmica e discurso político, conforme a própria autora salienta na introdução do trabalho. A historiadora demarca o tom de celebração a Cuba dado por Chris Marker em seu filme, pela recorrente articulação concebida pelo autor entre materiais de arquivos diversos (os de Cuba provenientes do Instituto Cubano del Arte e Industria Cinematográficos - ICAIC, e Gaumont) relacionados à voz over em tom literário. 
Os esforços analíticos de Aguiar nesse capítulo também estão direcionados a demonstrar o ensejo de Chris Marker a construir uma contrainformação, especialmente no que dizia respeito ao que a mídia francesa noticiava naquele momento sobre a experiência cubana. As entrelinhas do texto da historiadora revelam que há sempre um “de lá pra cá” no cinema de Chris Marker. O lugar de estrangeiro, o lá e cá de vozes com que o autor lida e se posiciona.

A partir de imagens do ICAIC enviadas à França, Chris Marker concebeu três filmes, analisados por Aguiar no segundo capítulo de seu livro. On vous parle du Brésil: tortures (1969), On vous parle du Brésil: Carlos Marighela (1970) e La bataille des dix millions (1970). Ao se voltar mais diretamente aos filmes dessa série, Carolina de Aguiar procurou diferenciar as estratégias adotadas na concepção dessas obras aos meios mais recorrentes no cinema do artista. Se no epistolar Lettre de Sibérie (1957), por exemplo, o endereçamento demarcava a pessoalidade das impressões de alguém que escreve "de um lugar distante", nesses filmes haveria um tom mais informativo e uma maior busca de objetividade. Diante dos horrores contidos nos arquivos a que tem acesso, Chris Marker entra em contato com a ditadura militar no Brasil e se posiciona também em relação a ela.

Um ponto importante que Aguiar esclarece diz respeito à relevância do ICAIC na conexão dos vários polos cinematográficos regionais latino-americanos e para além do continente. As obras de Chris Marker são demonstração significativa disso, já que ter à disposição os materiais do ICAIC foi fundamental como modo de construir uma "contrainformação", conforme anunciam as cartelas dos filmes da série On vous parle de Paris: Maspero, les monts ont un sens (1970), demarcando esse objetivo criativo.

É a partir de um desenho composto por uma percurso histórico sobre a situação política do Chile na década de 1960, e uma série de contatos estabelecidos por Chris Marker no país, que a autora constrói o terceiro capítulo do seu trabalho. Nesse momento são salientadas relações importantes, como a com Patricio Guzmán e com Armand Mattelard. Entre eles, um meio de campo europeu que envolve nomes como Joris Ivens, com quem Marker contribuiu em À Valparaíso (1963). O Chile desvelado por Aguiar é aquele constituído de grupos organizados, como a Unidade Popular, em torno da eleição de Salvador Allende, e também o Chile baqueado pós-golpe, que busca compreender suas experiências de luta e as circunstâncias da derrubada de Salvador Allende do poder.

O Chile segue como tema do quarto capítulo com o enfoque para a obra La spirale (1976), feita em uma parceria cinematográfico-sociológica entre Chris 
Marker e Armand Mattelart. Antes de dar enfoque à análise do filme, a autora considerou importante investigar a trajetória de Mattelart, de modo a pensar o encontro com o artista francês. É fundamental ter posta a tese sociológica de Mattelart sobre o golpe que derrubou Salvador Allende, de modo que o sociólogo sublinha o papel da articulação da burguesia apoiada pela mídia nesse processo. Essa reflexão estimulou Chris Marker a propor a parceria na direção do filme, que é enfoque central na pesquisa da autora.

O elemento que dá título ao filme, A espiral, também aparece no livro como forma que inspira as observações da autora, que identifica a relação estabelecida por Chris Marker com a história e o modo como isso se revela nas temáticas e nos aspectos formais de seus filmes. Nessa seção, Aguiar salienta o modo como a montagem associativa e discursiva - já nos anos 1970 aspecto marcante da obra de Chris Marker - contribui na articulação de materiais de arquivo de naturezas diversas, que argumenta de modo alinhado ao que propunha Mattelart em seus estudos.

O capítulo dedicado ao filme L’Ambassade (1974), inicialmente, já se lança ao trabalho de análise centrado na investigação sobre as estratégias utilizadas por Chris Marker para construir esse filme de caráter híbrido entre o documentário e a ficção. Nele convivem uma série de recursos que, segundo a autora, são mobilizados com o intuito de criar uma "ilusão". Mais uma vez, o trabalho de montagem é a chave do entendimento dos processos de associação que Marker deseja erigir. Algo que nos leva a pensar na análise feita no capítulo seguinte de Le fonde de l'air est rouge (O fundo do ar é vermelho, 1977), em que o trabalho de montagem, também com materiais vindos de fontes diversas, é concebido de forma a construir um discurso fílmico, ou um contra-discurso fílmico, que põe em contato as experiências latino-americanas e europeias de luta. A autora procura analisar exemplos em que a montagem associativa corrobora na construção de um dizer, de um argumento, e aquele ao qual ela chama atenção é o da montagem, que trabalha no sentido de articular gestos do cinema e da história, por exemplo, como no caso da análise da sequência em que Chris Marker reúne cenas de O encouraçado Potemkin (1925), e materiais de arquivo de cenas de luta na rua.

A grandiosa obra de Chris Marker de 1977 é analisada também de modo a perceber continuidades e permanências na abordagem do artista sobre determinados temas antes já tratados em sua filmografia, como é o caso da relação com Cuba, em Le fonde de l'air est rouge no filme de 1977 já vista de forma mais ambígua, inquieta conforme reforça Carolina Amaral de Aguiar citando também a autora Ursula Langmann (1986). 
Carolina Amaral de Aguiar(2016) conclui seu livro destacando aspectos comuns aos filmes de Chris Marker relacionados com a América Latina ao sublinhar "a busca pelo internacionalismo dos projetos políticos abordados" (p. 308) e "visão espiralada do tempo histórico" (p. 308)como características que unem os filmes do seu recorte. O seu trabalho triunfa ao buscar esmiuçar essas relações transcontinentais de modo a construir um desenho de comoções, envolvimentos, empatias, em que é através do contato que os filmes que desvelam as lutas se constituem.

\section{Referências}

AGUIAR, C. A. O cinema latino-americano de Chris Marker. São Paulo: Alameda, 2016.

BRUNO, N. Chris Marker e as barricadas da memória: comentários em torno de estrado P.: a memória da arte em "Sans Soleil". Dissertação (Mestrado) - Universidade Federal de São Carlos, São Carlos, 2013.

KOIDE, E. Por um outro cinema: jogo da memória em Chris Marker. Tese (Doutorado) - Universidade de São Paulo, São Paulo, 2011.

LANGMANN, U. O Manual da História idealizado. In: GRÉLIER, R. O bestiário de Chris Marker. Lisboa: Horizonte, 1986

LEONEL, B. N. A. Chris Marker e as barricadas da memória: comentários em torno de "Le fond de l'air est rouge". Dissertação (Mestrado) - Universidade de São Paulo, São Paulo, 2010.

Percursos da formação de Chris Marker: cinema militante, dissidência e profanação. Tese (Doutorado) - Universidade de São Paulo, São Paulo, 2015.

SELIGMANN-SILVA, M. História, memória, literatura: o testemunho na era das catástrofes. Campinas: Unicamp, 2003.

\section{Referências audiovisuais}

À VALPARAÍSO. Chris Marker, França-Chile, 1963.

BRONENOSETS Potyomkin (O encouraçado Potemkin). Nina Agadzhanova, Rússia, 1925.

¡CUBA sí! Chris Marker, França, 1961.

L'AMBASSADE. Chris Marker, França, 1974.

LA BATAILLE des dix millions. Chris Marker, França, 1970. 
LA JETÉE. Chris Marker, França, 1962.

LA SPIRALE. Chris Marker, França, 1976.

LE FONDE de l'air est rouge. Chris Marker, França, 1977.

LETTRE de Sibérie. Chris Marker, França, 1957.

ON VOUS parle du Brésil: Carlos Marighela. Chris Marker, França, 1971.

ON VOUS parle du Brésil: tortures. Chris Marker, França, 1969.

ON VOUS parle de Paris: Maspero, les monts ont un sens. Chris Marker, França, 1970. 